Bio-grafía. Escritos sobre la Biología y su Enseñanza. ISSN 2027-1034

Edición Extraordinaria. p.p. 201-213

Memorias del Primer encuentro ambiental Universidad, ambiente y sustentabilidad: experiencias y prácticas.

\title{
DETERMINACIÓN DE LA IMPORTANCIA DE LOS HUMEDALES EN LA CIUDAD DE BOGOTÁ D.C, A TRAVÉS DE PRUEBAS FISICOQUÍMICAS Y COMO EL IMPACTO DE LA INTERVENCIÓN DEL HOMBRE AFECTA ESTOS ECOSISTEMAS.
}

\author{
Chacón Pardo Angie Natalia ${ }^{1}$ \\ Pachón Márquez Paola Fernanda ${ }^{1}$ \\ Valero Vargas Jhon Gerardo ${ }^{1}$ \\ Velásquez Casallas Michael ${ }^{1}$
}

\section{Resumen}

El crecimiento de las problemáticas socio-ambientales genera la necesidad de estructurar herramientas educativas que faciliten la comprensión del manejo de sustentabilidad ambiental, por esta razón se decide trabajar en torno a la caracterización mediante pruebas fisicoquímicas de los humedales Juan Amarillo y La Conejera para estructurar e implementar una estrategia pedagógica que, posteriormente, permita concientizar a la comunidad sobre las problemáticas existentes en los afluentes descritos anteriormente. De igual manera, se pretende sistematizar cómo la intervención humana ha afectado a cada uno de los sistemas hídricos al considerar la protección del humedal de la Conejera con respecto al Juan Amarillo.

\section{Palabras Clave}

Humedal La Conejera, Humedal Juan Amarillo, calidad de agua,

${ }^{1}$ Universidad Pedagógica Nacional, Estudiante de Licenciatura en Química, SISMA Semillero de investigación en salud y medio ambiente.dqu_anchaconp970@pedagogica.edu.co, dqu_pfpachonm963@pedagogica.edu.co,dqu_jgvalerov080@pedagogica.edu.co, dqu_mvelasquezc600@pedagogica.edu.co 
Bio-grafía. Escritos sobre la Biología y su Enseñanza. ISSN 2027-1034

Edición Extraordinaria. p.p. 201-213

Memorias del Primer encuentro ambiental Universidad, ambiente y sustentabilidad: experiencias y prácticas.

\section{Abstract}

The growth of the environmental problems generated the need for structured educational tools that facilitate the understanding of sustainable environmental management, by this reason is decides to work on the characterization by testing physicochemical of them wetlands Juan Amarillo and La Conejera, for after, structuring and implementing an educational strategy that can educate the community on the problems existing in the tributaries described above. In the same way, is intended to systematize how human intervention affects each water systems to consider the protection of one of the two wetlands.

\section{Key Words}

La Conejera Wetland, Juan Amarillo wetland, water quality

\section{OBJETIVO GENERAL}

Caracterizar las condiciones ambientales de los humedales Juan Amarillo y la Conejera, de tal manera que pueda determinarse el impacto ambiental producido en ellos por la intervención a la que han estado sometidos.

\section{OBJETIVOS ESPECÍFICOS}

- Realizar y analizar pruebas cualitativas y cuantitativas, de agua, en los ecosistemas en estudio para determinar las condiciones en las que se encuentran.

- Determinar la importancia de estos ecosistemas en Bogotá y cómo se han visto afectados por el hombre.

- Diseñar una estrategia pedagógica y/o de divulgación para la socialización de los resultados de investigación que redunde en la protección de los ecosistemas en estudio. 
Bio-grafía. Escritos sobre la Biología y su Enseñanza. ISSN 2027-1034

Edición Extraordinaria. p.p. 201-213

Memorias del Primer encuentro ambiental Universidad, ambiente y sustentabilidad: experiencias y prácticas.

\section{MARCO TEÓRICO}

La ciudad de Bogotá, creció sobre y alrededor de los humedales de la sabana; estos se crearon desde la última glaciación. Dentro de su zona urbana se encuentran humedales de 3 tipos diferentes: Humedales de Páramo que están a una altitud mayor de los $3200 \mathrm{msnm}$, humedales de Ladera estos se encuentran entre los 2700 y $3200 \mathrm{msnm}$ y humedales de Planicie que están por debajo de los $2700 \mathrm{msnm}$.

Los ecosistemas Juan Amarillo y el de La Conejera, se clasifican como humedales de planicie, pero también se pueden considerar como lacustres ya que son aquellos que presentan una baja circulación de agua y un espejo de agua permanente (lago, laguna). (Emmanuel, 2016)

El humedal cumple unas funciones muy importantes como ecosistema, principalmente como una esponja, en donde se acumula, circula y libera agua. El proceso de acumulación de agua se presenta durante épocas de invierno y su importancia radica en ayudar a mitigar las inundaciones en la ciudad y actuar paralelamente como reservorio para épocas de sequía. Estos ecosistemas albergan gran cantidad de especies, biodiversidad endémica y migratoria ya que es un espacio vital para el desarrollo de la fauna y la flora de la ciudad, por ejemplo, en estos humedales se concentra gran variedad de especies como peces, aves, mamíferos, roedores e insectos en cuanto a fauna y en flora gran variedad de árboles, plantas acuáticas, terrestres o aéreas.

Actúa como retenedor de carbono, debido a la acidez, falta de oxígeno y nutrientes; así la materia orgánica que se concentra en el humedal se descompone y se acumula en el suelo. Esto es relevante frente al calentamiento global, pues este tipo de lugares aportan al mejoramiento de la calidad del aire, actúan como sumideros de $\mathrm{CO}_{2}$ y retenedores de polvo por ende regulan la temperatura del lugar en donde se encuentren; así mismo generan microclimas y son productores de oxígeno. (Alarcón, 2016) 
Bio-grafía. Escritos sobre la Biología y su Enseñanza. ISSN 2027-1034

Edición Extraordinaria. p.p. 201-213

Memorias del Primer encuentro ambiental Universidad, ambiente y sustentabilidad: experiencias y prácticas.

Por otra parte, se conoce que en estos afluentes hídricos se encuentran diferentes iones y/o compuestos disueltos, que pueden favorecer o afectar la calidad del agua. Por ello fueron realizadas diferentes pruebas para la determinación de estos iones en agua, el fundamento teórico que las respalda es el siguiente (León, 2005):

Amonio: Este compuesto se encuentra de manera natural en aguas superficiales y residuales. Por lo tanto su concentración acostumbra ser baja en aguas subterráneas ya que es retenido en partículas y arcillas del suelo. Se produce en gran parte por desaminación de los compuestos orgánicos nitrogenados

Dureza de carbonatos, residual y total: Revela la presencia de metales alcalinotérreos principalmente el magnesio y el calcio, ambos expresados en términos de dureza como carbonato cálcico. Este procedimiento se realiza de manera complementaria en los ensayos de toxicidad que requieran determinar la dureza esencialmente en aguas naturales, residuales y residuales tratadas.

Nitrato: Es un nutriente de muchos autótrofos fotosintéticos que se presenta, generalmente, como trazas en la superficie de agua, pero en niveles inferiores puede alcanzar mayores concentraciones. Se encuentra en pequeñas cantidades en aguas residuales y en algunas plantas de diluyentes tratamiento biológico nitrificante. En cantidades altas puede conducir a enfermedades en niños como la metahemoglobinemia.

Nitrito: Es un estado intermedio de la oxidación del nitrógeno, es agente de la enfermedad (metahemoglobinemia). Este agente puede formar ácido y reaccionar con aminas secundarias dando lugar así a nitrosamidas, que son agentes carcinógenos.

Fosfato: Se encuentra en aguas residuales como fosfatos que surgen de diversas fuentes. Muchos de los componentes de jabones para el lavado de ropa lo contienen, también es indispensable para el crecimiento de muchos 
Bio-grafía. Escritos sobre la Biología y su Enseñanza. ISSN 2027-1034

Edición Extraordinaria. p.p. 201-213

Memorias del Primer encuentro ambiental Universidad, ambiente y sustentabilidad: experiencias y prácticas.

microorganismos y puede ser un limitador en la productividad de un cuerpo de agua.

pH: es uno de los parámetros químicos que afecta ampliamente las reacciones químicas y biológicas que se llevan a cabo en el agua, llegando a generar alteraciones en la flora y fauna, y solubilidad de los nutrientes (cuando este posee valores muy altos), el rango propicio para el desarrollo de vida es de 6,0 y 7,4 .

\section{METODOLOGÍA}

El proyecto se planteó en tres fases de desarrollo mediante las cuales se pretende dar cumplimiento a los objetivos del mismo. Las fases son las siguientes:

Fase 1. Obtención de muestras de agua y análisis fisicoquímico de los humedales:

Se realizó una visita el día 7 de abril del 2016 a los humedales mencionados. Allí se tomaron catorce muestras de agua; seis en el humedal Juan Amarillo y ocho en el humedal de la Conejera, su ubicación puede verificarse en las imágenes 1 y 2 . Para su recolección se tuvo en cuenta las siguientes consideraciones: utilizar frascos de ámbar con el fin de que las muestras no se contaminaran ya que estos ayudan a la preservación de la muestra, cada uno de los frascos utilizados se purgó mínimo dos veces con el agua del lugar exacto de donde se tomó la muestra de agua, se procedió a la rotulación del frasco con datos como hora, fecha y una breve descripción de lugar, con el fin de no tener confusiones a la hora del análisis, cabe resaltar que el periodo en que fueron tomadas las muestras era tiempo seco.

Una vez recolectadas las muestras se procede a la realización de las pruebas fisicoquímicas entre los días 7 a 12 de abril del 2016. Para este procedimiento se utilizó un laboratorio compacto para análisis de agua con el que se realizaron pruebas de nitritos, nitratos, fosfatos, amonio, $\mathrm{pH}$, dureza residual, dureza total y carbonatos. 
Bio-grafía. Escritos sobre la Biología y su Enseñanza. ISSN 2027-1034

Edición Extraordinaria. p.p. 201-213

Memorias del Primer encuentro ambiental Universidad, ambiente y sustentabilidad: experiencias y prácticas.

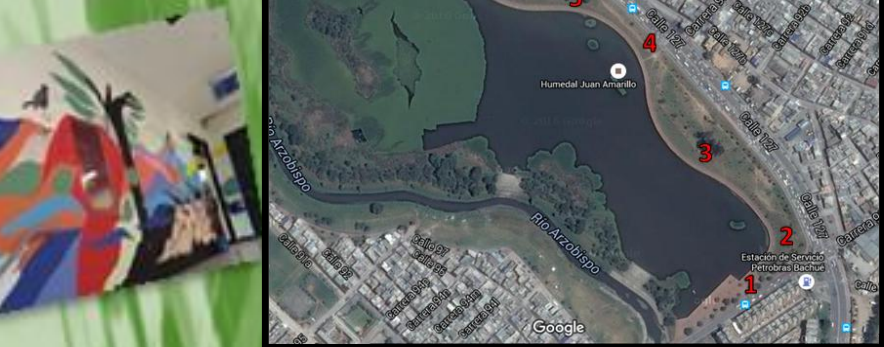

Imagen 1: Mapa humedal Juan Amarillo

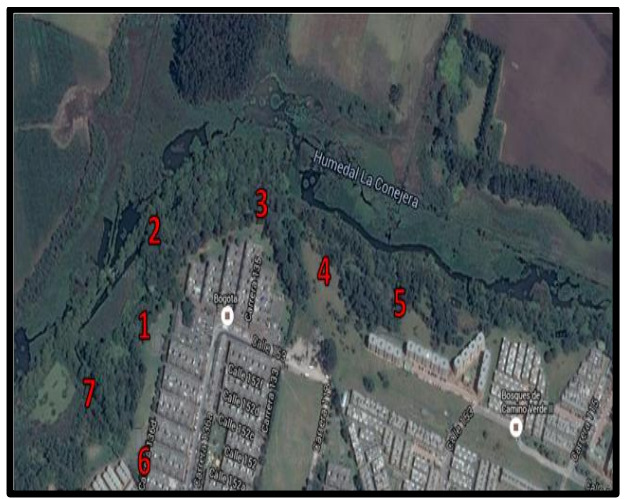

Imagen 2: Mapa humedal La Conejera (Google Maps, 2016)

Fase 2. Análisis de los resultados obtenidos: Se encuentra en desarrollo debido a que la información sobre los parámetros de calidad de sistemas hídricos de Bogotá no es asequible por ende se debe tramitar una serie de permisos a las diferentes entidades públicas y privadas que se encargan de la preservación de estos ecosistemas para realizar las diferentes comparaciones entre los resultados obtenidos y los esperados.

Fase 3. Diseño de la estrategia pedagógica con los resultados obtenidos: Esta fase comprende la creación de una estrategia pedagógica que conlleve a la concientización de la importancia de estos ecosistemas (humedal, Páramo) y cómo la intervención del hombre los afecta.

Proyección. Realizar las fases anteriores con páramos e inclusión de análisis de aire en los diferentes ecosistemas: Con el grupo de investigación EPISTEME de diseño tecnológico, se ha venido trabajando en un dispositivo (tarjeta Arduino) que mida la concentración de algunos gases contaminantes en partes por millón (PPP), con ese dispositivo se espera caracterizar a profundidad los parámetros ambientales.

\section{RESULTADOS}


Bio-grafía. Escritos sobre la Biología y su Enseñanza. ISSN 2027-1034

Edición Extraordinaria. p.p. 201-213

Memorias del Primer encuentro ambiental Universidad, ambiente y sustentabilidad: experiencias y prácticas.

\begin{tabular}{|c|c|c|c|c|c|c|c|c|c|c|c|c|c|c|}
\hline $\begin{array}{l}\text { \#muestra/ } \\
\text { prueba }\end{array}$ & pH & & $\begin{array}{l}\mathrm{Am} \\
\mathrm{mg} / \\
\mathrm{NH}\end{array}$ & $\begin{array}{l}\text { nio } \\
\text { L } \\
+\end{array}$ & $\begin{array}{l}\text { Nitr } \\
\text { mg/ } \\
\text { No }\end{array}$ & & $\begin{array}{l}\text { Fosf } \\
\text { mg/ } \\
\mathrm{PO}_{4}\end{array}$ & & $\begin{array}{l}\text { Dur } \\
\text { Tot } \\
\text { mg/ } \\
\mathrm{CaC}\end{array}$ & & $\begin{array}{l}\text { Dur } \\
\text { Res } \\
{ }^{\circ} \mathbf{d}\end{array}$ & $\begin{array}{l}\text { za } \\
\text { lual }\end{array}$ & $\begin{array}{l}\text { Dur } \\
\text { car } \\
{ }^{\circ} d\end{array}$ & natos \\
\hline Humedal & J.A & $\mathrm{C}$ & J.A & $\mathrm{C}$ & J.A & $\mathrm{C}$ & J.A & $\mathrm{C}$ & J.A & $\mathrm{C}$ & J.A & $\mathrm{C}$ & JA & $\mathrm{C}$ \\
\hline 1 & 6,90 & 6,94 & 0,2 & 3 & - & - & 0,25 & 0,75 & 25 & 60 & 0,5 & 0,5 & 1,8 & 4 \\
\hline 2 & 7,11 & 6,91 & - & 2 & - & 10 & - & 1 & 25 & 70 & 0,5 & 0,5 & 1,8 & 2,5 \\
\hline 3 & 7,00 & 6,96 & 0,2 & 3 & - & 10 & 0,25 & 1,25 & 23 & 60 & 0,5 & 0,5 & 2 & 2,5 \\
\hline 4 & 6,97 & 7,10 & 0,2 & 3 & - & - & 0,25 & 2 & 25 & 70 & 0,5 & 0,5 & 0,4 & 4,8 \\
\hline 5 & 7,02 & 6,89 & - & 2 & - & 10 & 0,25 & 2,7 & 25 & 80 & 0,5 & 0,5 & 0,4 & 8,5 \\
\hline 6 & 7,03 & 6,84 & - & 0,6 & - & 10 & - & 0,50 & 25 & 50 & 0,5 & 0,5 & 1,6 & 4,8 \\
\hline 7 & & 6,95 & & 1 & & 25 & & 1,5 & & 50 & & 0,5 & & 07 \\
\hline 8 & & 6,63 & & 2 & & - & & 3 & & 150 & & 0,5 & & 4 \\
\hline
\end{tabular}

Tabla 1. Resultados Pruebas Humedales Juan Amarillo y Conejera (J.A: Juan Amarillo C: Conejera)

`El test de nitrito no se logró determinar en ninguno de los dos humedales

ANÁLISIS DE RESULTADOS

\begin{tabular}{|c|c|c|}
\hline & Humedal Juan Amarillo & Humedal La Conejera \\
\hline & $\begin{array}{l}\text { Se encuentra ubicado en la } \\
\text { Carrera } 91 \text { A No } 127-00 \text { en las } \\
\text { localidades } 11^{\circ} \text { de Suba y } 10^{\circ} \\
\text { Engativá. Nace de la cuenca del } \\
\text { río Salitre y también lo alimenta el } \\
\text { río Negro. } \\
\text { Geográficamente se encuentra } \\
\text { entre las siguientes coordenadas: } \\
4^{\circ} 43^{\prime} 49.79^{\prime \prime} \mathrm{N}, 74^{\circ} 6^{\prime} 34.9^{\prime \prime} \text { W } \\
\text { cuenta con } 234 \text { hectáreas. }\end{array}$ & $\begin{array}{l}\text { Se ubica en la Carrera } 136 \text { D No.153- } \\
14 \text { Barrio Compartir Etapa I en la } \\
\text { localidad } 11^{\circ} \text { de Suba, y limita por el } \\
\text { norte con la vía Suba-Cota. El } \\
\text { humedal es alimentado por la } \\
\text { quebrada La Salitrosa. } \\
\text { Geográficamente se encuentra en } \\
\text { entre las siguientes coordenadas: } \\
4^{\circ} 45^{\prime} 42.02^{\prime \prime} \mathrm{N}, 74^{\circ} 6^{\prime} 18.05^{\prime \prime} \mathrm{W} \text {, } \\
\text { cuenta con } 60 \text { hectáreas. }\end{array}$ \\
\hline & \multicolumn{2}{|c|}{$\begin{array}{l}\text { Como se puede evidenciar ambos ecosistemas se encuentran en la misma } \\
\text { localidad lo que hace que sus microclimas, condiciones geográficas, } \\
\text { biodiversidad, parámetros fisicoquímicos tales como calidad de agua y aire } \\
\text { sean comparables, además atraviesan por problemáticas similares. }\end{array}$} \\
\hline
\end{tabular}


Bio-grafía. Escritos sobre la Biología y su Enseñanza. ISSN 2027-1034

Edición Extraordinaria. p.p. 201-213

Memorias del Primer encuentro ambiental Universidad, ambiente y sustentabilidad: experiencias y prácticas.

En este humedal se evidencia que el acceso a la comunidad no es restringido, por ello hay gente viviendo en su interior y generando todo tipo de desechos que, como se evidenció en la visita, muchas veces van a parar en el cuerpo hídrico del mismo.

El mal manejo de los residuos ocasiona que el Juan Amarillo se vea directamente afectado. Los índices de contaminación aumentan de manera exponencial, este se encuentra al lado de una vía principal con alto flujo vehicular, es considerado uno de los humedales más contaminado a lo largo de la historia.
La Conejera se encontraba como sitio público protegido, por consiguiente el acceso a la comunidad era más restringido, a pesar de ello se evidencia que hay dos o tres lugares por los cuales la comunidad puede acceder sin permiso alguno. Al quitar todo tipo de protección sobre este ecosistema, se evidencian los mismos problemas socioambientales que presenta el humedal Juan Amarillo.

La comunidad que habita alrededor de este lugar no le da la importancia a su protección y conservación, depositando muchos de sus residuos al ecosistema, ayudando a que sus índices de contaminación aumentan, a este lo surte hídricamente la quebrada salitrosa, de la cual no se tiene un control adecuado. 
Bio-grafía. Escritos sobre la Biología y su Enseñanza. ISSN 2027-1034

Edición Extraordinaria. p.p. 201-213

Memorias del Primer encuentro ambiental Universidad, ambiente y sustentabilidad: experiencias y prácticas.

La contaminación auditiva y la concurrencia existente en la zona, dificulta la propagación de las diversas especies que habitan el lugar. Algunas especies logran adaptarse a estos cambios drásticos, sin embargo, muchas otras se encuentran en vía de extinción, en la visita realizada se puede evidenciar que la fauna que allí habita lo hace con grandes afecciones, que se pueden detectar fácilmente, por ejemplo, algunas aves tienen sus extremidades enfermas.
La protección que poseía conllevaba a una mejoría de las condiciones de fauna y su ubicación geográfica hace que exista una mayor cantidad de aves y su eventual regreso también, se evidenció la presencia de anfibios, y variedad de insectos importantes en la polinización. Este ecosistema es uno de los sitios más importantes de avistamiento de aves de la ciudad y en él año 2013 fue declarado lugar de conservación de aves.
Es poco abundante, a lo largo del jarillón construido en el año 2002 se evidencia la presencia del buchón y helecho de agua que al ser plantas exóticas, y encontrarse en exceso puede afectar la oxigenación del cuerpo hídrico del humedal además de cubrir

los espejos de agua, a alrededores encontramos vegetación común, es decir, no es característica del tipo de humedal.
En la Conejera se evidencia gran variedad de flora y vegetación característica de este tipo de ecosistema, que en el momento que se encontraba protegido lograba mantener el ambiente biológico propio de este lugar, ya que la mayoría de las personas y las diferentes

organizaciones que tenían acceso al humedal cuidan de él, en conjunto con las entidades que se encargan de su protección. Al quitar la protección estas condiciones ambientales se ven afectadas drásticamente. 
Bio-grafía. Escritos sobre la Biología y su Enseñanza. ISSN 2027-1034

Edición Extraordinaria. p.p. 201-213

Memorias del Primer encuentro ambiental Universidad, ambiente y sustentabilidad: experiencias y prácticas.

Este lugar no cuenta con entes de control que regulen la entrada y salida de personas, por consiguiente, muchas personas viven en su interior, causando grandes problemas de inseguridad, las autoridades tampoco se encuentran en el humedal.
Como se mencionaba con anterioridad este ecosistema estaba protegido por el acueducto de Bogotá y el jardín botánico, lo mantenían cercado, para ingresar se hablaba con las personas encargadas de verificar las intenciones con las cuales se dirigen al humedal, lo cual ayudaba a la conservación del mismo. Ya no cuenta con este mismo tipo de protección y se ven problemas de inseguridad como en El Juan Amarillo, donde hay gente instalada en el humedal y problemas de delincuencia

Tabla 2. Análisis de resultados de pruebas Humedales Juan Amarillo y Conejera
(J.A: Juan Amarillo C: Conejera)

\section{CONCLUSIONES}

A partir de las diversas pruebas fisicoquímicas se puede evidenciar cómo la intervención humana afecta de manera directa al desarrollo adecuado de los ecosistemas en estudio. Para este caso en particular, se tuvo en cuenta la ubicación de los humedales para realizar, de igual manera, una comparación considerando las similitudes ambientales entre los dos afluentes.

Mediante la caracterización de los humedales Juan Amarillo y La Conejera se puede evidenciar cómo en la actualidad, la protección de este tipo de ecosistemas es tan esencial para su conservación. La restricción de acceso en el humedal Juan Amarillo es prácticamente nula por lo cual la concentración de habitantes dentro del sistema ha aumentado exponencialmente, esto ha generado crecimiento en la producción de basuras, contaminación en el agua y disminución en la flora y fauna 
Bio-grafía. Escritos sobre la Biología y su Enseñanza. ISSN 2027-1034

Edición Extraordinaria. p.p. 201-213

Memorias del Primer encuentro ambiental Universidad, ambiente y sustentabilidad: experiencias y prácticas.

característica. Por otro lado, en el humedal La Conejera (que se encontraba protegido cuando se tomaron las muestras) se evidencia que el impacto ambiental era menor en comparación con el humedal Juan Amarillo, sin embargo por la falta de conciencia de la comunidad, se genera producción de basuras que se concentran dentro del afluente hídrico, generando contaminación directa en el ecosistema, debido a la desprotección de este ambiente se evidencian un crecimiento de las diferentes problemáticas socioambientales.

Además, las pruebas fisicoquímicas permiten evidenciar las dificultades del desarrollo del humedal Juan Amarillo por la ausencia de protección ambiental e intervención humana. La concentración de sales en el humedal La Conejera es mayor en comparación a la del humedal Juan Amarillo, lo que favorece la cadena trófica. Además la flora y fauna, por tratarse de un ambiente protegido, ha podido desarrollarse y permanecer dentro del ecosistema. Para finalizar, el desarrollo de esta investigación permite reflexionar acerca de las problemáticas socioambientales que actualmente están incrementando, el manejo de procedimientos físico-químicos que permiten evidenciar cómo la intervención humana genera consecuencias en este caso, sobre los sistemas hídricos, genera la necesidad de pensar acerca de la construcción de herramientas que permitan concientizar a la comunidad sobre las problemáticas descritas en el presente artículo lo cual, es indispensable para la formación de ciudadanos capaces de tomar decisiones responsables ante tales situaciones. Por esta razón, se proyecta la estructuración de una estrategia pedagógica para el fortalecimiento de la educación ambiental esencial para disminuir las problemáticas socio ambientales generadas por la intervención humana. 
Bio-grafía. Escritos sobre la Biología y su Enseñanza. ISSN 2027-1034

Edición Extraordinaria. p.p. 201-213

Memorias del Primer encuentro ambiental Universidad, ambiente y sustentabilidad: experiencias y prácticas.

\section{REFERENCIAS BIBLIOGRÁFICAS}

Google Maps. (17 de abril de 2016). Obtenido de Mapa de Humedal Juan Amarillo:

https://www.google.com.co/maps/place/Humedal+Juan+Amarillo/@4.738438 $3,-74.1176307,17 z /$ data

Google Maps. (17 de abril de 2016). Obtenido de Mapa de Humedal la Conejera,

Colombia:

https://www.google.com.co/maps/place/Humedal+La+Conejera/@4.7624624 ,-74.1130905,15z/data

Humedales Bogotá. (1 de mayo de 2016). Obtenido de Construcciones amenazan el humedal la conejea:

http://humedalesbogota.com/2014/09/02/construcciones-amenazan-elhumedal-la-conejera/

Alarcón, J. L. (2016). INECOL. Obtenido de Los humedales, sus funciones y su papel en el almacenamiento de carbono atmosférico: http://www.ecologia.edu.mx/inecol/index.php/es/ct-menu-item-25/ct-menuitem-27/172-los-humedales-sus-funciones-y-su-papel-en-el-almacenamientodel-carbono

Bernal, D. (7 de mayo de 2016). Humedales Bogotá. Obtenido de Top amenazas y problemas de los humedales bogotanos: http://humedalesbogota.com/2015/11/24/top-amenazas-y-problemas-de-loshumedales-bogotanos/ 
Bio-grafía. Escritos sobre la Biología y su Enseñanza. ISSN 2027-1034

Edición Extraordinaria. p.p. 201-213

Memorias del Primer encuentro ambiental Universidad, ambiente y sustentabilidad: experiencias y prácticas.

Bernal, D. (1 de mayo de 2016). Humedales Bogotá. Obtenido de Los humedales y Enrique Peñalosa. Caso tibabuyes o Juan Amarillo: http://humedalesbogota.com/2015/10/28/los-humedales-y-enrique-penalosaparte-1-tibabuyes-juan-amarillo/

Brausin Pulido Dora, L. P. (7 de mayo de 2016). Universidad colegio mayor de nuestra señora del rosario. Obtenido de Ecosistema del humedal tibabuyes: valoración cultural para el patrimonio natural: http://repository.urosario.edu.co/bitstream/handle/10336/4314/526924692013.pdf?sequence $=1$

Emmanuel, J. (7 de mayo de 2016). Humedales Bogotá. Obtenido de Ganadería en los humedales de Bogotá: http://humedalesbogota.com/2011/03/04/ganado-en-los-humedales-debogota/

León, J. A. (2005). Calidad de Aguas Para Estudiantes de Ciencias Ambientales. Bogotá: Universidad Distrital Francisco.

Méndez, O. D. (25 de junio de 2015). Fundación Humedales. Obtenido de ¿Por qué proteger el humedal de la conejera?: http://humedalesbogota.com/2015/06/25/por-que-proteger-el-humedal-laconejera/ 